By BEN C. BOWMAN

\title{
Xerography, Possible Solution to The Bad-Paper Book Problem
}

$\mathrm{I}^{\mathrm{N}}$ 1719, according to Dard Hunter, Rene Antoine Ferchault de Réaumur first suggested wood as a substitute for rag or linen in the manufacture of paper. By 1885 , sulphite pulp was being manufactured and used extensively in the United States. Today, the question of how best to preserve and, at the same time, make available the vast literary, historical, and scholarly record committed to pulp paper is a vexing problem for librarians. This seems especially true of research collections, wherein the question applies to materials which differ widely in kind, monetary value, availability for replacement, and intrinsic value. The purpose of these remarks is to describe briefly one library's possible answers to this question and to invite comment and suggestion from others who may find them of interest.

At the Newberry Library we continually are faced with the well known problem of what to do about books which are essential, expensive to replace (if indeed they can be found at all), and printed on paper so poor that any repair or rebinding is impractical. Dust is the destiny of such books, it seems, no matter how carefully they are used.

During the past year we have selected a few of these books and made Xerox editions-of-one for circulation copies. At present, Newberry makes a $35 \mathrm{~mm}$. microfilm on its own camera and sends the negative to a Xerox processing company in Chicago which operates continuous Xerox printers developed recently

Mr. Bowman is Assistant Librarian, Newberry Library, Chicago, Illinois. by the Haloid Xerox Company. The results are quite satisfactory reading copies of a number of books Newberry was about to lose by reader erosion and for which it had expended considerable time and effort to obtain replacements, as well as to prevent careless handling.

The cost of obtaining such a reading copy is, of course, relative. Depending upon the size of the original book, either two or four pages can be photographed per exposure. The more pages per exposure of film, the more pages per foot of Xerox paper, and this means lower cost of reproduction. Whether or not to make a Xerox copy for circulation also depends upon availability and price, and upon intrinsic value, for no research collection will want to replace everything automatically and without appraisal. Some books are best allowed, if not encouraged, to go their way to "dusty death."

A book that would seem to be an ideal candidate for Xerox replacement is Volume IV of Yale Studies in English. It is an essay about Dryden that merits preservation; it is printed on bad paper; it is not easily found; it runs to 110 pages only; it measures $6 \times 3 \frac{1}{2}$ inches, ideal dimensions for four pages per exposure; it was published in 1898. Newberry, consequently, made a Xerox copy of the book and introduced it into circulation. While our cost study of these Xerox replacements has not been carried out to the last penny, it is clear that this particular replacement cost well under five dollars for the complete job - camera time, binding, and handling.

This use of xerography has been ap- 
plied to other books at Newberry, books much less suited to economical reproduction. For example, various volumes of the British Calendars were originally manufactured interspersed with gatherings of varying length of very poor quality sulphite pulp. Wherever these volumes are heavily used, it is not long before they are either unusable or withdrawn from circulation. At Newberry, in terms of their intrinsic value, the cost of taking out the bad-paper sections, xeroxing, and binding them into a volume with the good-paper sections was not found excessive. By the time one has gone this far with Xerox and the problem of bad paper, a number of questions about the process, its practicality, its economy, and its general application manifest themselves.

First, of course, are any other libraries doing something similar? Volume III, No. 4, of Microcosm announces the installation of a Xerox continuous printer at University Microfilms and prices for the prints. The existence in combination of a Xerox continuous printer and a large negative microfilm archive suggests a second question for the bad-paper problem: Can multiple use of negatives be made practical? If Newberry has made a negative microfilm of Volume IV of Yale Studies in English, from which a Xerox edition-of-one can be made for a reasonable price, are there other libraries which also might want such an edition? Compiling a list of available microfilm negatives and circulating it might be worth while for re- search collections wanting to use Xerography for replacing bad-paper items. At present, the negatives Newberry retains from the Xerox processing company in Chicago are not given an archival wash. This poses questions of standards, storage, and preservation. Working out costs and prices is another matter for makers of negatives and buyers of prints to consider. The least expensive Xerox prints are on twenty-pound sulphite paper, but the Xerox continuous printers can turn out prints on papers of different quality. Paper more expensive than twenty-pound sulphite means, of course, an increase in cost.

In any event, when one research library has found it practical and economical to Xerox an essential or valuable bad-paper book from its collection, it seems desirable to give thought to the possibility of multiple use of the microfilm negative by other libraries wanting a like replacement of the same book.

Recently, for example, while Newberry was considering the advisability of xeroxing an 1871 scholarly edition of Boethius printed on bad paper, an interlibrary loan request for the book came from Columbia. This coincidence suggests that a standardized, locatable, and perhaps centrally deposited negative microfilm of a needed but disintegrating book would be an asset to research libraries, and enable them to cooperate in acquiring replacements, in book form, of items that do not necessarily fall within the scope of the reprint projects.

\section{MALC at Carbondale}

The Midwest Academic Librarians Conference was held on the campus of Southern Illinois University, Carbondale, April 25 and 26. The conference, designed for professional staff of academic libraries in the seven midwestern states, was addressed on Friday evening by Francis H. Horn, former president of Pratt Institute. On Saturday morning, Robert H. Muller, assistant director, University of Michigan Libraries, led a panel discussion on the question "What Is Professional?" 